\title{
Impact of the second internal thoracic artery on short- and long-term outcomes in obese patients: A propensity score matched analysis
}

\author{
Umberto Benedetto, MD, PhD, Alessandro Montecalvo, MD, Hassan Kattach, MD, \\ Mohamed Amrani, MD, PhD, FETCS, and Shahzad G. Raja, MRCS, FRCS(C-Th), on behalf of the \\ Harefield Cardiac Outcomes Research Group
}

\begin{abstract}
Objectives: A limited number of patients undergoing coronary artery bypass grafting (CABG) currently receive bilateral internal thoracic arteries (BITA) as a consequence of lack of evidence on survival benefit and concerns about sternal wound complications. This study was undertaken to determine the impact of BITA grafting on short- and long-term outcomes in obese patients.
\end{abstract}

Methods: Propensity score matching for short- and long-term outcomes was conducted for 1522 obese (body mass index $\left.\geq 30 \mathrm{~kg} / \mathrm{m}^{2}\right)$ patients undergoing CABG using BITA $(\mathrm{n}=229,15.0 \%)$ or a single internal thoracic artery (SITA, $\mathrm{n}=1293,85.0 \%$ ).

\begin{abstract}
Results: Propensity score matching created 229 matching sets. In the matched sample, operative mortality (within 30 days) occurred in $3(1.3 \%)$ and $4(1.7 \%)$ patients in the BITA and SITA groups, respectively $(P=1)$. Deep sternal wound infection occurred in $6(2.6 \%)$ and $2(0.9 \%)$ patients $(P=.2)$ in the BITA and SITA group, respectively. After a median follow-up of $4.5 \pm 3.3$ years, the use of BITA was associated with an improved late survival (hazard ratio [HR], 0.35; 95\% confidence interval $[\mathrm{CI}], 0.13-0.97 ; P=.03$ ) and a reduced need for repeat revascularization $(\mathrm{HR}, 0.45 ; 95 \% \mathrm{CI}, 0.23-0.85 ; P=.01)$.
\end{abstract}

Conclusions: BITA grafting can be safely offered to obese patients with significant long-term advantages without substantial additional risk of operative complications including deep sternal wound infection. (J Thorac Cardiovasc Surg 2015;149:841-7)

See related commentary on pages 848-9.

Supplemental material is available online.

With the prevalence of overweight and obese individuals estimated at $68 \%$, the significance of obesity in western countries has become a focus of increasing attention. ${ }^{1}$ The impact of high body mass index (BMI) on late outcomes after coronary artery bypass grafting (CABG) has been investigated by several studies. ${ }^{2-6}$ Although the results are conflicting with a few studies suggesting a protective relationship ${ }^{2}$ and others showing no effect, ${ }^{3-5}$ obesity has been consistently associated with increased operative

\footnotetext{
From the Department of Cardiac Surgery, Harefield Hospital, London, United Kingdom.

Disclosures: Authors have nothing to disclose with regard to commercial support.

Received for publication May 28, 2014; revisions received Aug 8, 2014; accepted for publication Aug 18, 2014; available ahead of print Oct 5, 2014.

Address for reprints: Umberto Benedetto, MD, PhD, Department of Cardiac Surgery, Harefield Hospital, London, UB9 6JH, United Kingdom (E-mail: umberto. benedetto@hotmail.com).

$0022-5223 / \$ 36.00$

Copyright (c) 2015 by The American Association for Thoracic Surgery http://dx.doi.org/10.1016/j.jtcvs.2014.08.060
}

morbidity and poorer long-term survival. ${ }^{3-7}$ The detrimental effect of obesity on long-term survival after CABG has been attributed to the progression of earlier atherogenic grafts observed in patients with higher BMI, which may lead to a greater risk of clinical events at long-term follow-up. ${ }^{8}$

The use of a second internal thoracic artery over saphenous vein grafts (SVG) has been consistently reported to improve long-term outcomes after $\mathrm{CABG}$, including overall survival. ${ }^{9,10}$ The main reason for the long-term benefit from the use of a second internal thoracic artery has been attributed to its better patency rate ${ }^{11}$ secondary to the reduced susceptibility to atherosclerosis compared with SVG. ${ }^{12}$ Although such a benefit is expected to be enhanced in patients with higher BMI, ${ }^{11,13}$ surgeons continue to be reluctant to perform bilateral internal thoracic artery (BITA) grafting in obese patients, ${ }^{14}$ because of the lack of evidence of a longterm benefit in such a high-risk group. Furthermore, concerns still exist regarding the detrimental effect of this strategy on operative outcomes, including the potential vulnerability for sternal wound complications in such a high-risk group. ${ }^{5,14-16}$ Therefore, there is an urgent need to validate the safety and efficacy of BITA grafting for obese patients requiring CABG. We undertook a single-center propensity matched outcomes analysis to evaluate the impact of BITA compared with single internal thoracic artery (SITA) on short- and long-term outcomes in obese patients. 


$$
\begin{aligned}
& \text { Abbreviations and Acronyms } \\
& \text { BITA }=\text { bilateral internal thoracic arteries } \\
& \text { BMI }=\text { body mass index } \\
& \text { CABG }=\text { coronary artery bypass grafting } \\
& \text { COPD }=\text { chronic obstructive pulmonary disease } \\
& \text { CVA }=\text { cerebrovascular accident } \\
& \text { DSWI }=\text { deep sternal wound infection } \\
& \text { HR }=\text { hazard ratio } \\
& \text { LAD }=\text { left anterior descending } \\
& \text { LVEF }=\text { left ventricular ejection fraction } \\
& \text { NYHA }=\text { New York Heart Association } \\
& \text { PCI }=\text { percutaneous coronary intervention } \\
& \text { POAF }=\text { postoperative atrial fibrillation } \\
& \text { PVD }=\text { peripheral vascular disease } \\
& \text { RRT }=\text { renal replacement therapy } \\
& \text { SITA }=\text { single internal thoracic artery } \\
& \text { SMD }=\text { standardized mean difference } \\
& \text { SVG }=\text { saphenous vein grafts }
\end{aligned}
$$

\section{METHODS \\ Study Population}

The study was conducted in accordance with the principles of the Declaration of Helsinki. The local ethical committee approved the study, and the requirement for individual patient consent was waived. We retrospectively analyzed prospectively collected data from the institutional surgical database (PATS; Dendrite Clinical Systems, Ltd, Oxford, UK) from April 2001 to May 2013. The PATS database captures detailed information on a wide range of preoperative, intraoperative, and hospital postoperative variables (including complications and mortality) for all patients who underwent CABG surgery in our institution. The data are collected and reported in accordance with the Society for Cardiothoracic Surgery in Great Britain \& Ireland database criteria. The database is maintained by a team of full-time clinical information analysts, who are responsible for continuous prospective data collection as part of a continuous audit process. Data collection is validated regularly. We classified anyone with a BMI of $30 \mathrm{~kg} / \mathrm{m}^{2}$ and higher as obese, in line with the National Heart Lung and Blood Institute classification of obesity. ${ }^{17}$ All patients who met the following criteria were included in the analysis: (1) first time isolated CABG; (2) BMI greater than or equal to $30 \mathrm{~kg} / \mathrm{m}^{2}$; (3) 2 or more grafts received; (4) surgical strategies included SITA to left anterior descending (LAD) artery and additional SVG for non-LAD targets (SITA group) or BITA with or without additional SVG (BITA group). All patients included were eligible for the use of BITA and the choice of BITA was based on the surgeon's preference.

The study population consisted of 1522 obese patients who received CABG using BITA $(n=229,15.0 \%)$ or SITA $(n=1293,85.0 \%)$. Median BMI was 33 (interquartile range, 31-35; maximum 50). In the BITA group, the right internal thoracic artery was used as in situ retrosternal conduit to the LAD in 135 cases (in these cases, the left internal thoracic artery was used as in situ conduit to graft the diagonal branch in 11 cases and the circumflex territory in 124), as an in situ retroaortic conduit to the circumflex territory in 61 cases, as a $\mathrm{Y}$ graft to the circumflex territory in 21 cases, to graft to the right coronary artery in 12 cases $(6$ cases in situ conduit, 6 cases as free conduit). A total of 145 of $229(63 \%)$ patients in the BITA group received at least an SVG. BITA were harvested as skeletonized conduits in 100 of $229(43 \%)$.

\section{Pretreatment Variables and Study End Points}

The effect of BITA was adjusted for 18 pretreatment variables: age, female gender, New York Heart Association (NYHA) functional class III-IV, previous myocardial infarction, previous percutaneous coronary intervention (PCI), diabetes mellitus, current smoking, chronic obstructive pulmonary disease (COPD), previous cerebrovascular accident (CVA), peripheral vascular disease (PVD), preoperative atrial fibrillation, left main stem disease, number of vessels diseased, left ventricular ejection fraction (LVEF) less than $50 \%$, renal impairment defined as a serum creatinine level more than $200 \mathrm{mmol} / \mathrm{L}$, urgent/emergency indication, preoperative use of an intra-aortic balloon pump, and the use of cardiopulmonary bypass.

The short-term outcomes investigated were the incidence of deep sternal wound infection (DSWI) as defined by the Centers for Disease Control and Prevention, ${ }^{18}$ postoperative CVA, need for renal replacement therapy (RRT), reintubation for acute respiratory failure, reexploration for bleeding, postoperative atrial fibrillation (POAF), prolonged length of hospital stay ( $\geq 8$ days corresponding to the 75 th percentile), and operative mortality (within 30 days).

Long-term outcomes investigated were all-cause late mortality and freedom from repeat revascularization including the need for PCI or redo CABG. All-cause death is the most robust and unbiased index because no adjudication is required, thus avoiding inaccurate or biased documentation and clinical assessments. ${ }^{19}$ Information about death from any cause is obtained regularly from the General Register Office approximately 1 week after the event and data on repeat revascularization are obtained from the national surgical and interventional database.

\section{Statistical Analysis}

For baseline characteristics, variables are summarized as the mean for continuous variables and the proportion for categorical variables.

Multiple imputation using a bootstrapping-based expectationmaximization algorithm was used to address missing data. The fraction missing ranged from $0 \%$ (age) to $0.6 \%$ (number of vessels diseased). Patterns of missingness in the data were 23 and rows after listwise deletion were 1456. Rows after imputation were 1522 and the imputation models showed normal expectation-maximization convergence. ${ }^{20}$

To control for measured potential confounders in the data set, a propensity score was generated for each patient from a multivariable logistic regression model based on 18 pretreatment covariates as independent variables with treatment type (BITA vs SITA) as a binary dependent variable. ${ }^{21}$ The resulting propensity score represented the probability of a patient undergoing CABG with BITA grafting (C statistic, 0.77). Pairs of patients receiving BITA and SITA were derived using greedy $1: 1$ matching with a caliper of width of 0.20 standard deviation of the logit of the propensity score. The quality of the match was assessed by comparing selected pretreatment variables in propensity score matched patients using the standardized mean difference (SMD), by which an absolute standardized difference of greater than $10 \%$ is suggested to represent meaningful covariate imbalance. Analytical methods for the estimation of the treatment effect in the matched sample included the McNemar test to compare proportions. Kaplan-Meier survival curves between treated and untreated patients in the matched sample were compared using a test described by Austin and Therneau. ${ }^{22,23}$ Baseline characteristics and outcomes were also reported for the unmatched SITA patients (Tables E1 and E2, Figures E1 and E2).

$\mathrm{R}$ version 3.1.0 was used for the statistical analysis. ${ }^{24}$

\section{RESULTS}

\section{Propensity Score Matching}

Table 1 summarizes for each pretreatment variable, the unmatched and matched prevalence for the treatment group 
TABLE 1. Pretreatment variables distribution before and after matching

\begin{tabular}{|c|c|c|c|c|c|c|c|c|c|c|}
\hline & \multicolumn{2}{|c|}{ BITA $(N=229)$} & \multicolumn{2}{|c|}{ UM-SITA $(N=1293)$} & \multirow{2}{*}{$\begin{array}{c}\text { SMD before } \\
\text { matching }\end{array}$} & \multirow{2}{*}{$\begin{array}{l}P \text { before } \\
\text { matching }\end{array}$} & \multicolumn{2}{|c|}{ M-SITA } & \multirow{2}{*}{$\begin{array}{c}\text { SMD after } \\
\text { matching }\end{array}$} & \multirow{2}{*}{$\begin{array}{c}P \text { after } \\
\text { matching }\end{array}$} \\
\hline & $\mathbf{n}$ & $\%$ & $\mathbf{n}$ & $\%$ & & & $\mathbf{n}$ & $\%$ & & \\
\hline \multicolumn{11}{|l|}{$\overline{\text { Age }}$} \\
\hline$<50 \mathrm{y}$ & 33 & 14.4 & 60 & 4.6 & 75 & $<.001$ & 30 & 13.1 & 6 & .49 \\
\hline $50-59 y$ & 90 & 39.3 & 273 & 21.1 & & & 93 & 40.6 & & \\
\hline $60-69 y$ & 77 & 33.6 & 443 & 34.3 & & & 58 & 25.3 & & \\
\hline $70-79 y$ & 26 & 11.4 & 451 & 34.9 & & & 46 & 20.1 & & \\
\hline$\geq 80 \mathrm{y}$ & 3 & 1.3 & 66 & 5.1 & & & 2 & 0.9 & & \\
\hline \multicolumn{11}{|l|}{ Female } \\
\hline No & 203 & 88.6 & 983 & 76.0 & 33 & $<.001$ & 206 & 90.0 & 4 & .76 \\
\hline Yes & 26 & 11.4 & 310 & 24.0 & & & 23 & 10.0 & & \\
\hline \multicolumn{11}{|l|}{ NYHA III/IV } \\
\hline No & 177 & 77.3 & 823 & 63.7 & 30 & $<.001$ & 177 & 77.3 & 0 & 1 \\
\hline Yes & 52 & 22.7 & 470 & 36.3 & & & 52 & 22.7 & & \\
\hline \multicolumn{11}{|l|}{ MI } \\
\hline No & 132 & 57.6 & 773 & 59.8 & 4 & .59 & 124 & 54.1 & 7 & .5 \\
\hline Yes & 97 & 42.4 & 520 & 40.2 & & & 105 & 45.9 & & \\
\hline \multicolumn{11}{|l|}{ PCI } \\
\hline No & 187 & 81.7 & 1095 & 84.7 & 8 & .28 & 185 & 80.8 & 2 & .9 \\
\hline Yes & 42 & 18.3 & 198 & 15.3 & & & 44 & 19.2 & & \\
\hline \multicolumn{11}{|l|}{ Current smoking } \\
\hline No & 205 & 89.5 & 1158 & 89.6 & 0.1 & 1 & 210 & 91.7 & 7 & .52 \\
\hline Yes & 24 & 10.5 & 135 & 10.4 & & & 19 & 8.3 & & \\
\hline \multicolumn{11}{|l|}{ COPD } \\
\hline No & 212 & 92.6 & 1138 & 88.0 & 15 & .05 & 208 & 90.8 & 6 & .61 \\
\hline Yes & 17 & 7.4 & 155 & 12.0 & & & 21 & 9.2 & & \\
\hline \multicolumn{11}{|l|}{ CVA } \\
\hline No & 220 & 96.1 & 1207 & 93.3 & 12 & .15 & 218 & 95.2 & 4 & .81 \\
\hline Yes & 9 & 3.9 & 86 & 6.7 & & & 11 & 4.8 & & \\
\hline \multicolumn{11}{|l|}{ PVD } \\
\hline No & 219 & 95.7 & 1186 & 91.8 & 16 & .05 & 222 & 97.0 & 7 & .6 \\
\hline Yes & 10 & 4.3 & 107 & 8.2 & & & 7 & 3.0 & & \\
\hline $\mathrm{AF}$ & & & & & & & & & & \\
\hline No & 223 & 97.4 & 1240 & 95.9 & 8 & .37 & 221 & 96.5 & 5 & .68 \\
\hline Yes & 6 & 2.6 & 53 & 4.1 & & & 8 & 3.5 & & \\
\hline LVEF $<50 \%$ & & & & & & & & & & \\
\hline No & 197 & 86.0 & 1032 & 79.8 & 16 & .03 & 195 & 85.2 & 2 & .89 \\
\hline Yes & 32 & 14.0 & 261 & 20.2 & & & 34 & 14.8 & & \\
\hline Creatinine & & & & & & & & & & \\
\hline$>200 \mu \mathrm{mol}$ & & & & & & & & & & \\
\hline No & 0 & 0.0 & 1255 & 97.1 & 24 & .01 & 0 & 0.0 & 0 & 1 \\
\hline Yes & 0 & 0.0 & 38 & 2.9 & & & 0 & 0.0 & & \\
\hline Diabetes mellitu & & & & & & & & & & \\
\hline No & 189 & 82.5 & 810 & 62.6 & 45 & $<.001$ & 192 & 83.8 & 3 & .8 \\
\hline Yes & 40 & 17.5 & 483 & 37.4 & & & 37 & 16.2 & & \\
\hline Preoperative IAF & & & & & & & & & & \\
\hline No & 223 & 97.4 & 1247 & 96.4 & 5 & 6 & 223 & 97.4 & 0 & 1 \\
\hline Yes & 6 & 2.6 & 46 & 3.6 & & & 6 & 2.6 & & \\
\hline Vessels diseased & & & & & & & & & & \\
\hline DIAG & 6 & 2.6 & 70 & 5.4 & 3.8 & .58 & 12 & 5.2 & 8 & .38 \\
\hline CX or RCA & 62 & 27.1 & 305 & 23.6 & & & 40 & 17.5 & & \\
\hline $\mathrm{CX}$ and RCA & 161 & 70.3 & 918 & 71.0 & & & 177 & 77.3 & & \\
\hline LMD & & & & & & & & & & \\
\hline No & 154 & 67.2 & 957 & 74.0 & 14 & .04 & 150 & 65.5 & 3 & .76 \\
\hline Yes & 75 & 32.8 & 336 & 26.0 & & & 79 & 34.5 & & \\
\hline
\end{tabular}


TABLE 1. Continued

\begin{tabular}{|c|c|c|c|c|c|c|c|c|c|c|}
\hline & \multicolumn{2}{|c|}{ BITA $(N=229)$} & \multicolumn{2}{|c|}{ UM-SITA $(N=1293)$} & \multirow{2}{*}{$\begin{array}{l}\text { SMD before } \\
\text { matching }\end{array}$} & \multirow{2}{*}{$\begin{array}{l}P \text { before } \\
\text { matching }\end{array}$} & \multicolumn{2}{|c|}{ M-SITA } & \multirow{2}{*}{$\begin{array}{l}\text { SMD after } \\
\text { matching }\end{array}$} & \multirow{2}{*}{$\begin{array}{c}P \text { after } \\
\text { matching }\end{array}$} \\
\hline & $\mathbf{n}$ & $\%$ & $\mathbf{n}$ & $\%$ & & & $\mathbf{n}$ & $\%$ & & \\
\hline \multicolumn{11}{|c|}{ Urgent/emergency } \\
\hline No & 153 & 66.8 & 911 & 70.5 & 7 & .3 & 154 & 67.2 & 0.9 & 1 \\
\hline Yes & 76 & 33.2 & 382 & 29.5 & & & 75 & 32.8 & & \\
\hline \multicolumn{11}{|l|}{$\mathrm{CPB}$} \\
\hline No & 157 & 68.6 & 845 & 65.4 & 7 & .38 & 151 & 65.9 & 5 & .61 \\
\hline Yes & 72 & 31.4 & 448 & 34.6 & & & 78 & 34.1 & & \\
\hline
\end{tabular}

BITA, Bilateral internal thoracic arteries; SITA, single internal thoracic artery; UM, unmatched; $M$, matched; SMD, standardized mean difference; NYHA, New York Heart Association; $M I$, myocardial infarction; $P C I$, percutaneous coronary intervention; $C O P D$, chronic obstructive pulmonary disease; $C V A$, cerebrovascular accident; $P V D$, peripheral vascular disease; $A F$, atrial fibrillation; $L V E F$, left ventricular ejection fraction; $I A B P$, intra-aortic balloon pump; $C X$, circumflex artery; $R C A$, right coronary artery; $L M D$, left main stem disease; $C P B$, cardiopulmonary bypass; DIAG, diagonal.

(BITA) and the control group (SITA) with the relative SMD and $P$ value. Before matching, patients receiving SITA were significantly different from those receiving BITA; overall, the SMD of 10 of 18 pretreatment covariates was equal to or higher than 10 . Specifically, patients receiving SITA presented a higher risk profile, being older, more likely to be female and to have a functional NYHA class III/IV, COPD, previous CVA, PVD, left LVEF less than $50 \%$, a baseline creatinine level of $200 \mu \mathrm{mol} / \mathrm{L}$ or more, diabetes mellitus, and left main stem coronary disease.

Propensity score matching created a total of 229 matching sets. After matching, all covariates were well balanced between the 2 groups with SMD less than $10 \%$ for all pretreatment variables.

\section{Short-Term Outcomes in the Matched Sample}

Table 2 summarizes the short-term outcomes investigated for the matched BITA and SITA groups. Overall, operative mortality (within 30 days) occurred in 3 $(1.3 \%)$ and $4(1.7 \%)$ patients in the matched BITA and SITA groups, respectively $(P=1)$. DSWI occurred in $6(2.6 \%)$ and $2(0.9 \%)$ patients in the BITA and SITA groups, respectively $(P=.2)$. Among BITA patients, DSWI occurred in 2 of $100(2.0 \%)$ patients receiving skeletonized BITA and 4 of 129 (3.1\%) patients receiving pedicled BITA $(P=.6)$. The risk for DSWI was significantly associated with BMI $(P=.005)$ but not with the use of BITA regardless of the gender or the presence of diabetes mellitus (Figure 1). With regard to other postoperative complications, the 2 groups did not differ for the incidence of reexploration for bleeding $(P=1)$, reintubation $(P=.3)$, postoperative RRT $(P=1)$, postoperative CVA $(P=.4)$, and POAF $(P=.9)$. The incidence of prolonged length of hospital stay ( $\geq 8$ days) was comparable between the 2 groups $(P=.13)$. Compared with SITA patients, BITA patients received a higher number of grafts $(2.88 \pm 0.74$ vs $2.71 \pm 0.82$; $P=.002)$.

\section{Long-Term Outcomes in the Matched Sample}

In the matched sample, a total of 20 deaths (5 BITA, 15 SITA) and 44 cases of repeat revascularization (13 BITA, 31 SITA) occurred after a median follow-up of $4.5 \pm 3.3$ years. Survival probability was $97.7 \% \pm 1.0 \%$ versus $93.2 \% \pm 1.8 \%$ at 5 years, and $97.7 \% \pm 1.0 \%$ versus $92.1 \% \pm 2.1 \%$ at 10 years in the BITA and the SITA groups, respectively. Compared with SITA, the use of BITA was associated with a significantly lower late mortality rate (hazard ratio [HR], 0.35; 95\% confidence

TABLE 2. Short-tem outcomes in the matched BITA and SITA groups

\begin{tabular}{|c|c|c|c|c|c|}
\hline & \multicolumn{2}{|c|}{ BITA $(N=229)$} & \multicolumn{2}{|c|}{ SITA $(\mathbf{N}=229)$} & \multirow[b]{2}{*}{$\boldsymbol{P}$} \\
\hline & $\mathbf{n}$ & $\%$ & $\mathbf{n}$ & $\%$ & \\
\hline \multicolumn{6}{|c|}{ 30-d mortality } \\
\hline No & 226 & 98.7 & 225 & 98.3 & 1 \\
\hline Yes & 3 & 1.3 & 4 & 1.7 & \\
\hline \multicolumn{6}{|l|}{ DSWI } \\
\hline No & 223 & 97.4 & 227 & 99.1 & .2 \\
\hline Yes & 6 & 2.6 & 2 & 0.9 & \\
\hline \multicolumn{6}{|c|}{ Postoperative CVA } \\
\hline No & 227 & 99.1 & 229 & 100.0 & .4 \\
\hline Yes & 2 & 0.9 & 0 & 0.0 & \\
\hline \multicolumn{6}{|c|}{ Postoperative RRT } \\
\hline No & 221 & 96.5 & 222 & 96.9 & 1 \\
\hline Yes & 8 & 3.5 & 7 & 3.1 & \\
\hline \multicolumn{6}{|l|}{ POAF } \\
\hline No & 185 & 80.8 & 187 & 81.7 & .9 \\
\hline Yes & 44 & 19.2 & 42 & 18.3 & \\
\hline \multicolumn{6}{|c|}{ Reintubation } \\
\hline No & 217 & 94.8 & 222 & 96.9 & .3 \\
\hline Yes & 12 & 5.2 & 7 & 3.1 & \\
\hline \multicolumn{6}{|c|}{ Reexploration } \\
\hline No & 218 & 95.2 & 218 & 95.2 & 1 \\
\hline Yes & 11 & 4.8 & 11 & 4.8 & \\
\hline \multicolumn{6}{|c|}{$\begin{array}{l}\text { Prolonged length of } \\
\text { hospital stay }(\geq 8 \mathrm{~d})\end{array}$} \\
\hline No & 146 & 36.8 & 148 & 64.6 & .13 \\
\hline Yes & 83 & 36.2 & 81 & 35.4 & \\
\hline
\end{tabular}

BITA, Bilateral internal thoracic arteries; SITA, single internal thoracic artery; DSWI, deep sternal wound infection; $C V A$, cerebrovascular accident; $R R T$, renal replacement therapy; $P O A F$, postoperative atrial fibrillation. 

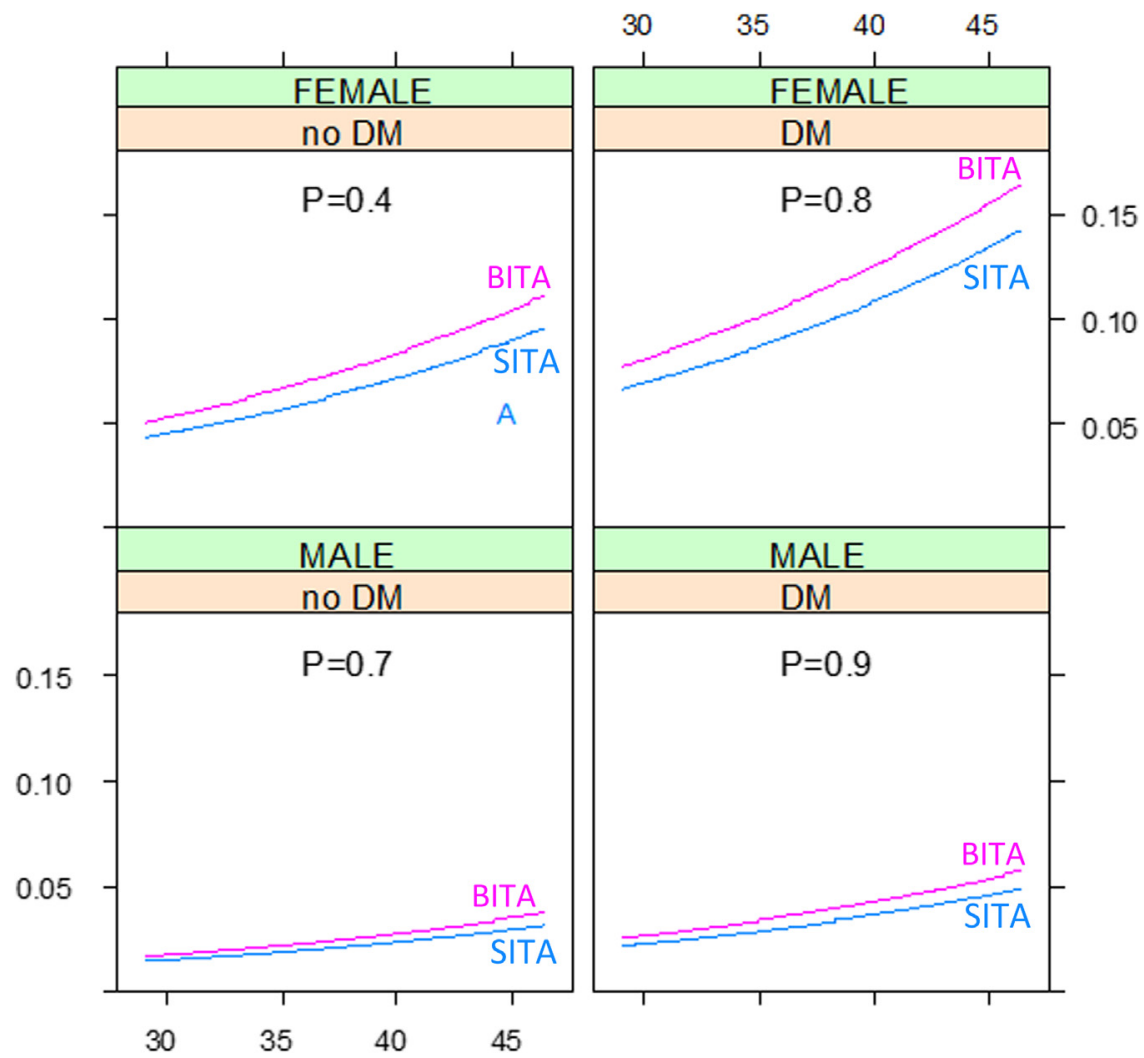

BMI

FIGURE 1. Predicted risk (fraction) of deep sternal wound infection in the bilateral internal thoracic arteries (BITA) and single internal thoracic artery (SITA) groups across body mass index $(B M I)$ values adjusted for gender and the presence of diabetes mellitus $(D M)$.

interval $[\mathrm{CI}], 0.13-0.97 ; \quad P=.03$; Figure 2). The probability of repeat revascularization-free survival was $93.6 \% \pm 1.7 \%$ versus $86.6 \% \pm 2.5 \%$ at 5 years and $93.6 \% \pm 1.7 \%$ versus $78.9 \% \pm 4.1 \%$ at 10 years in the BITA and the SITA groups, respectively. Compared with SITA, the use of BITA was associated with a significantly lower need for repeat revascularization (HR, 0.45; 95\% CI, 0.23-0.85; $P=.01$; Figure 3).

\section{DISCUSSION}

The main finding of the present study was that, in obese patients undergoing CABG, the use of BITA did not increase operative morbidity and mortality and it was associated with better long-term outcomes including improved late survival and reduced need for repeat revascularization.

Obesity (BMI $\geq 30 \mathrm{~kg} / \mathrm{m}^{2}$ ) has been consistently demonstrated to affect long-term survival after $\mathrm{CABG} .^{3-7}$ Such a detrimental effect may be partially explained by the accelerated atherogenic graft progression observed in obese patients. ${ }^{8}$ Given the established relationship of atherosclerotic progression with long-term clinical events, ${ }^{13}$ obesity is expected to lead to a demonstrably greater risk of clinical events with longer follow-up; the lack of a detrimental effect from obesity on post-CABG outcomes reported by sporadic studies ${ }^{2,25,26}$ has been related to their limited follow-up.

The use of a second internal thoracic artery over an SVG has been consistently reported to significantly improve clinical outcomes including long-term survival after CABG. ${ }^{9,10}$ The long-term benefit from the use of a second internal thoracic artery has been attributed to its reduced susceptibility to atherosclerosis and consequent improved patency rate compared with an SVG. ${ }^{11}$ This benefit is anticipated to be enhanced in obese patients as a consequence of their accelerated atherogenic graft disease. ${ }^{8}$

However, no previous study has investigated the impact of BITA grafting on long-term outcomes in obese patients. Moreover, the potential vulnerability of obese patients to DSWI as a result of BITA grafting still remains a matter of controversy. ${ }^{27,28}$ Because of the lack of evidence of a long-term benefit, surgeons are still reluctant to adopt BITA grafting for obese patients and this strategy is currently denied for most obese patients referred for CABG. BITA grafting has been previously reported to be used in only $5.3 \%$ of obese patients undergoing CABG. ${ }^{14}$ 


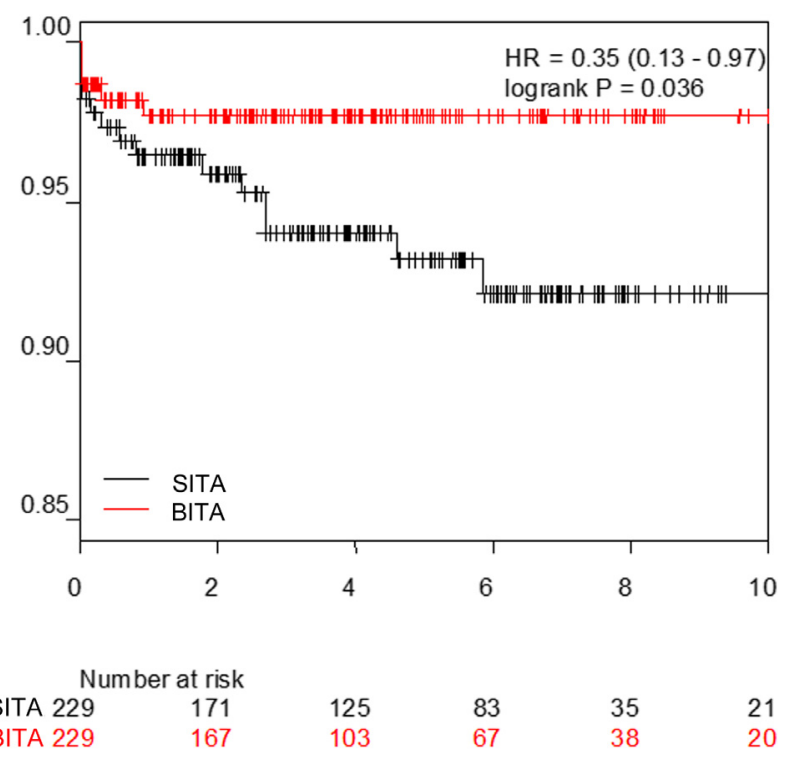

FIGURE 2. Kaplan-Meier analysis for overall survival in the matched bilateral internal thoracic arteries (BITA) and single internal thoracic artery (SITA) groups. HR, Hazard ratio.

This report is likely to be among the very few that have focused on the impact of the use of BITA in obese patients. We found that, compared with SITA grafting, BITA grafting was associated with a $65 \%$ absolute risk reduction for late death and a $55 \%$ absolute risk reduction for the need for repeat revascularization. The use BITA was not associated with a significantly increased risk for DSWI in this high-risk subgroup across all BMI values, regardless of gender and the presence of diabetes. As previously reported,

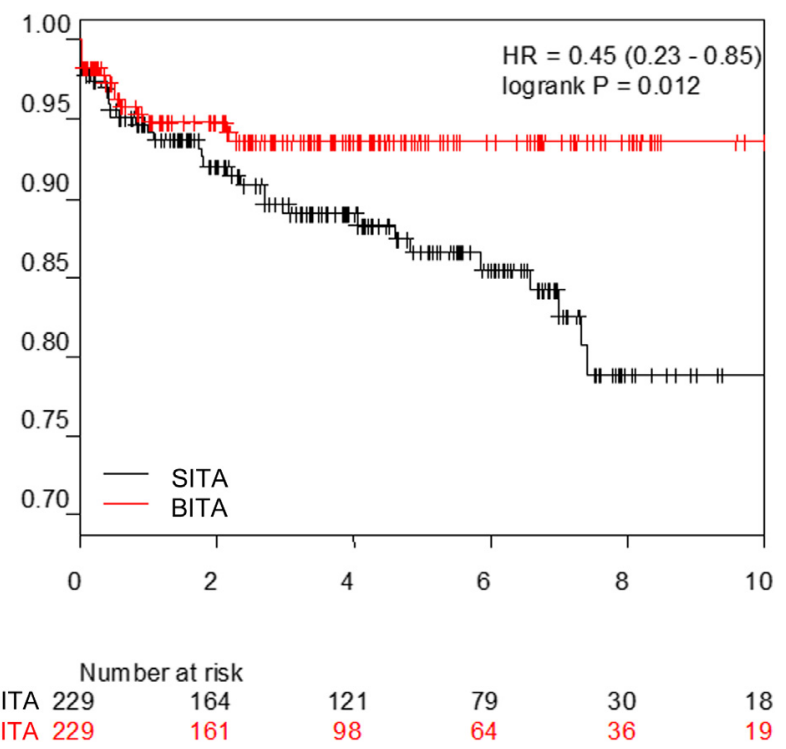

FIGURE 3. Kaplan-Meier analysis for repeat revascularization-free survival in the matched bilateral internal thoracic arteries (BITA) and single internal thoracic artery (SITA) groups. HR, Hazard ratio. we observed a nonsignificant trend toward a lower incidence of DSWI when BITA were harvested as skeletonized conduits. $^{29}$

Although obesity has been reported to be associated with a higher incidence of DSWI, ${ }^{5,16}$ controversy still exists regarding the detrimental role of BITA harvesting on sternal complications in obese patients. ${ }^{14}$ Our results challenge the general notion that routine use of BITA in obese predisposes the patients to increased risk of DSWI and are consistent with conclusions of previous studies. Puskas and colleagues ${ }^{14}$ could not demonstrate that the use of BITA added an extra risk for DSWI among 205 patients with a BMI of $30 \mathrm{~kg} / \mathrm{m}^{2}$ or higher. In a recent report on 1,526,360 patients from the US Nationwide Inpatient Sample who underwent isolated CABG, BITA grafting was associated with increased risk of DSWI only in patients with severe chronic diabetes but not in obese patients. ${ }^{30}$ Furthermore, it is difficult to assess the effect of BITA harvesting in isolation because there is still little standardization of the practice in relation to stabilization of the sternum, which may have the main impact on the incidence of sternal complications. As obese patients may especially benefit from BITA when technically feasible and safe, it would therefore be important to define subsets of patients who are at significantly higher risk of DSWI. Our findings suggest that the risk of DSWI is remarkable among female patients, in particular those with diabetes, although BITA did not significantly increase the risk (Figure 1). However, further well-powered studies are needed to estimate the impact of BITA in such a high-risk subgroup and extra caution should be taken when considering the use of BITA in high-risk obese patients.

The principal limitation of the present analysis is the inability to address hidden biases due to unobserved or unrecorded differences between treated and control patients before treatment. As a consequence, our results could reflect the effects of unknown or unmeasured confounders. We did not measure the changes in the BMI during the follow-up period; hence, no causality of the interrelationship between these parameters could be determined. In addition, obesity was defined only by the BMI in the present study, rather than by an actual measure of adiposity, such as the waist circumference. ${ }^{31}$ However, the BMI is a widely available, simple, and practical measurement of obesity, and numerous studies have used BMI as a surrogate measure of adiposity.

In conclusion, BITA grafting should be considered in obese patients (BMI $\geq 30 \mathrm{~kg} / \mathrm{m}^{2}$ ) because of the significant long-term advantages obtained with this surgical technique with no additional risk of operative complications including DSWI. This could become the optimal surgical revascularization strategy in such a high-risk subgroup. Further randomized studies on patients with increased BMI are needed to support these findings. 
We thank all consultant cardiac surgeons who operated at Harefield Hospital during the study period for their contribution: M. Amrani, T. Bahrami, F. de Robertis, G. Dreyfus, J. Gaer, A. Khaghani, A. Moza, S. G. Raja, A. Simon, and S. Tadjkarimi.

\section{References}

1. Flegal KM, Caroll MD, Ogden CL, Curtin LR. Prevalence and trends in obesity among US adults, 1999-2008. JAMA. 2010;303:235-41.

2. Stamou SC, Nussbaum M, Stiegel RM, Reames MK, Skipper ER, Robicsek F, et al. Effect of body mass index on outcomes after cardiac surgery: is there an obesity paradox? Ann Thorac Surg. 2011;91:42-7.

3. Benedetto U, Danese C, Codispoti M. Obesity paradox in coronary artery bypass grafting: myth or reality? J Thorac Cardiovasc Surg. 2014;147: $1517-23$.

4. van Straten AH, Bramer S, Soliman Hamad MA, van Zundert AA, Martens EJ, Schonberger JP, et al. Effect of body mass index on early and late mortality after coronary artery bypass grafting. Ann Thorac Surg. 2010; 89:30-7.

5. Habib RH, Zacharias A, Schwann TA, Riordan CJ, Durham SJ, Shah A. Effects of obesity and small body size on operative and long-term outcomes of coronary artery bypass surgery: a propensity-matched analysis. Ann Thorac Surg. 2005; 79:1976-86.

6. Kuduvalli M, Grayson AD, Oo AY, Fabri BM, Rashid A. The effect of obesity on mid-term survival following coronary artery bypass surgery. Eur J Cardiothorac Surg. 2003;23:368-73.

7. Gurm HS, Whitlow PL, Kip KE, BARI Investigators. The impact of body mass index on short- and long-term outcomes in patients undergoing coronary revascularization: insights from the Bypass Angioplasty Revascularization Investigation (BARI). J Am Coll Cardiol. 2002;39:834-40.

8. Wee CC, Girotra S, Weinstein AR, Mittleman MA, Mukamal KJ The relationship between obesity and atherosclerotic progression and prognosis among patients with coronary artery bypass grafts the effect of aggressive statin therapy. J Am Coll Cardiol. 2008;52:620-5.

9. Lytle BW, Blackstone EH, Loop FD, Houghtaling PL, Arnold JH, Akhrass R, et al. Two internal thoracic artery grafts are better than one. J Thorac Cardiovasc Surg. 1999;117:855-72.

10. Weiss AJ, Zhao S, Tian DH, Taggart DP, Yan TD. A meta-analysis comparing bilateral internal mammary artery with left internal mammary artery for coronary artery bypass grafting. Ann Cardiothorac Surg. 2013;2:390-400.

11. Benedetto U, Raja SG, Albanese A, Amrani M, Biondi-Zoccai G, Frati G. Searching for the second best graft for coronary artery bypass surgery: a network meta-analysis of randomized controlled trials. Eur J Cardiothorac Surg. March 30, 2014. http://dx.doi.org/10.1093/ejcts/ezu111 [Epub ahead of print].

12. He GW, Liu ZG. Comparison of nitric oxide release and endothelium-derived hyperpolarizing factor-mediated hyperpolarization between human radial and internal mammary arteries. Circulation. 2001;104(Suppl):I344-9.

13. Knatterud GL, White C, Geller NL, Campeau L, Forman SA, Domanski M, et al. Angiographic changes in saphenous vein grafts are predictors of clinical outcomes. Am Heart J. 2003;145:262-9.

14. Pusca SV, Kilgo PD, Vega JD, Cooper WA, Vassiliades TA, Chen EP, et al. Propensity-score analysis of early outcomes after bilateral versus single internal thoracic artery grafting. Innovations. 2008;3:19-24.
15. Ioannidis JPA, Galanos O, Katritsis D, Connery CP, Drossos GE, Swistel DG, et al. Early mortality and morbidity of bilateral versus single internal thoracic artery revascularization: propensity and risk modeling. J Am Coll Cardiol. 2001;37:521-8.

16. Lindhout AH, Wouters CW, Noyez L. Influence of obesity on in-hospital and early mortality and morbidity after myocardial revascularization. Eur J Cardiothorac Surg. 2004;26:535-41.

17. World Health Organization. Obesity: preventing and managing the global epidemic. Report of a WHO consultation. World Health Organ Tech Rep Ser. 2000:894:1-12.

18. Garner JS, Jarvis WR, Emori TG, Horan TC, Hughes JM. CDC definitions for nosocomial infections, 1988. Am J Infect Control. 1988;16: $128-40$.

19. Lauer MS, Blackstone EH, Young JB, Topol EJ. Cause of death in clinical research: time for a reassessment? J Am Coll Cardiol. 1999:34:618-20.

20. Honaker J, King G, Blackwell M. Amelia II: A program for missing data. J Stat Softw. 2011;45:1-47.

21. Stampf S. Nonrandom: stratification and matching by the propensity score. $\mathrm{R}$ package version 1.42. 2014. Available at: http://CRAN.R-project.org/ package $=$ nonrandom. Accessed April 15, 2014.

22. Austin PC. An introduction to propensity score methods for reducing the effects of confounding in observational studies. Multivariate Behav Res. 2011;46: 399-424.

23. Therneau T. A package for survival analysis in $\mathrm{S}$. $\mathrm{R}$ package version 2.37-7. Available at: http://CRAN.R-project.org/package=survival. Accessed April 15, 2014.

24. $\mathrm{R}$ Core Team. $R$ : A language and environment for statistical computing. Vienna, Austria: R Foundation for Statistical Computing; 2014. ISBN 3-900051-07-0.

25. Gruberg L, Mercado N, Milo S, Boersma E, Disco C, van Es GA, et al., Arterial Revascularization Therapies Study Investigators. Impact of body mass index on the outcome of patients with multivessel disease randomized to either coronary artery bypass grafting or stenting in the ARTS trial: the obesity paradox II? Am J Cardiol. 2005;95:439-44.

26. Kim J, Hammar N, Jakobsson K, Luepker RV, McGovern PG, Ivert T. Obesity and the risk of early and late mortality after coronary artery bypass graft surgery. Am Heart J. 2003; 146:555-6.

27. Loop FD, Lytle BW, Cosgrove DM, Mahfood S, McHenry MC, Goormastic M, et al. Sternal wound complications after isolated coronary bypass grafting: early and late mortality, morbidity and cost of care. Ann Thorac Surg. 1990; 49:179-87.

28. Burfeind WR, Glower DD, Wechsler AS, Tuttle RH, Shaw LK, Harrell FE, et al Single versus multiple internal mammary artery grafting for coronary artery bypass. 15-Year follow-up of a clinical practice trial. Circulation. 2004;110 II27-35.

29. Sá MP, Ferraz PE, Escobar RR, Vasconcelos FP, Ferraz AA, Braile DM et al. Skeletonized versus pedicled internal thoracic artery and risk of sternal wound infection after coronary bypass surgery: meta-analysis and meta-regression of 4817 patients. Interact Cardiovasc Thorac Surg. 2013; 16:849-57.

30. Itagaki S, Cavallaro P, Adams DH, Chikwe J. Bilateral internal mammary artery grafts, mortality and morbidity: an analysis of 1526360 coronary bypass operations. Heart. 2013;99:849-53.

31. Jago R, Mendoza JA, Chen T, Baranowski T. Longitudinal associations between BMI, waist circumference, and cardiometabolic risk in US youth: monitoring implications. Obesity (Silver Spring). 2013;21:E271-9. 


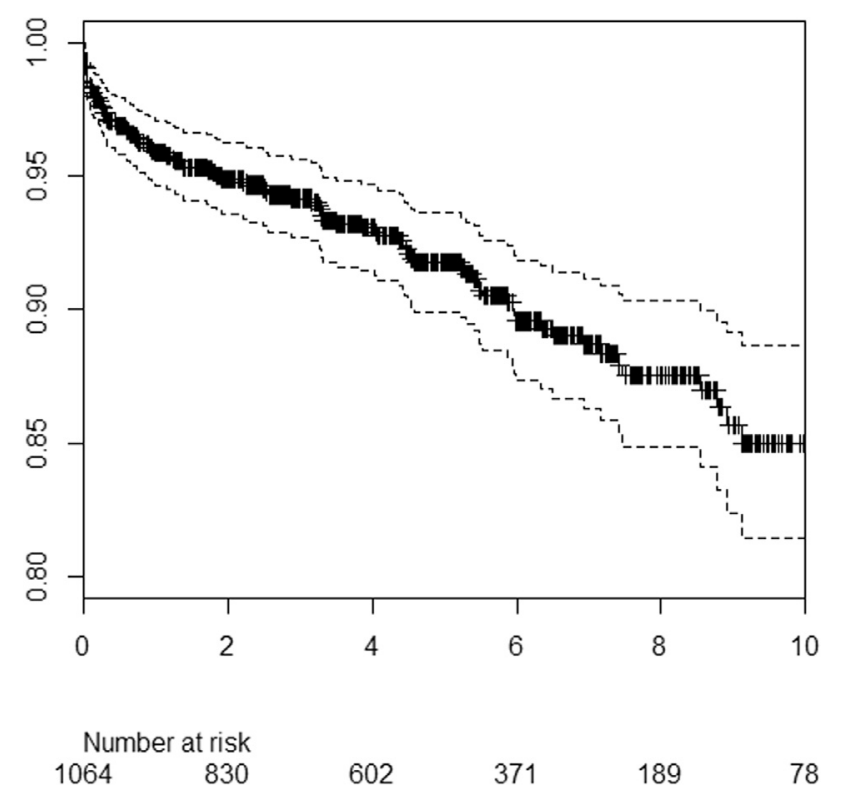

FIGURE E1. Kaplan-Meier analysis for overall survival among unmatched and single internal thoracic artery patients.

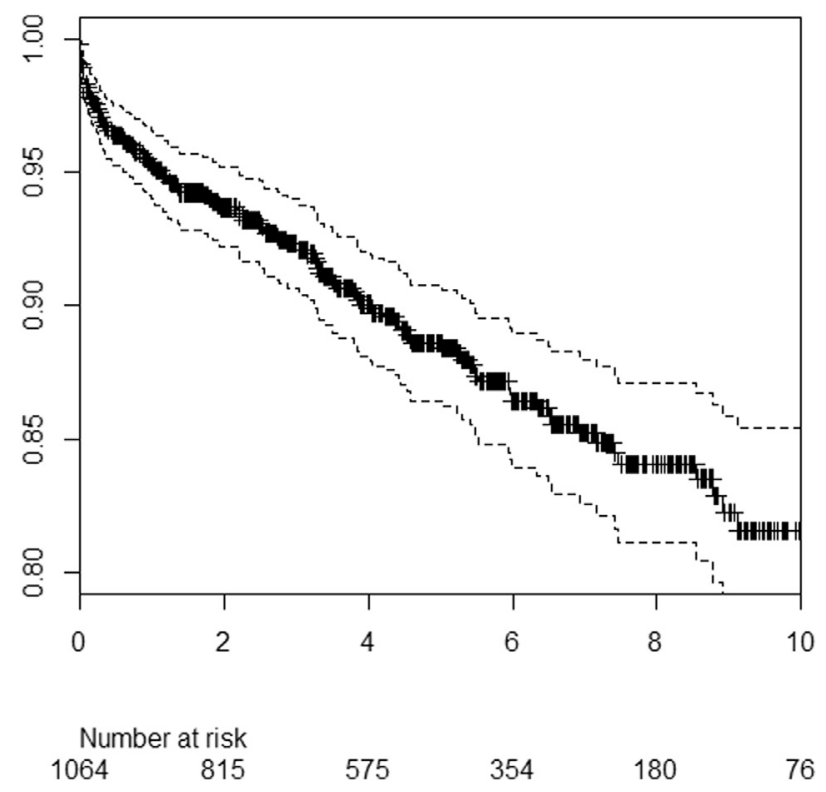

FIGURE E2. Kaplan-Meier analysis for repeat revascularization-free survival among unmatched and single internal thoracic artery patients. 
TABLE E1. Baseline characteristics in the unmatched patients with a single internal thoracic artery $($ SITA) $(n=1064)$

\begin{tabular}{|c|c|c|}
\hline Variable & $\mathbf{N}$ & $\%$ \\
\hline \multicolumn{3}{|l|}{ Age } \\
\hline$<50 \mathrm{y}$ & 30 & 2.8 \\
\hline $50-59$ y & 180 & 16.9 \\
\hline $60-69$ y & 385 & 36.2 \\
\hline $70-79$ y & 405 & 38.1 \\
\hline$\geq 80 \mathrm{y}$ & 64 & 6.0 \\
\hline \multicolumn{3}{|l|}{ Female } \\
\hline No & 777 & 73.0 \\
\hline Yes & 287 & 27.0 \\
\hline \multicolumn{3}{|l|}{ NYHA III/IV } \\
\hline No & 646 & 60.7 \\
\hline Yes & 418 & 39.3 \\
\hline \multicolumn{3}{|l|}{ MI } \\
\hline No & 649 & 61.0 \\
\hline Yes & 415 & 39.0 \\
\hline \multicolumn{3}{|l|}{ PCI } \\
\hline No & 910 & 85.5 \\
\hline Yes & 154 & 14.5 \\
\hline \multicolumn{3}{|l|}{ Current smoking } \\
\hline No & 948 & 89.1 \\
\hline Yes & 116 & 10.9 \\
\hline \multicolumn{3}{|l|}{ COPD } \\
\hline No & 930 & 87.4 \\
\hline Yes & 134 & 12.6 \\
\hline \multicolumn{3}{|l|}{ CVA } \\
\hline No & 989 & 93.0 \\
\hline Yes & 75 & 7.0 \\
\hline \multicolumn{3}{|l|}{ PVD } \\
\hline No & 964 & 90.7 \\
\hline Yes & 100 & 9.3 \\
\hline \multicolumn{3}{|l|}{$\mathrm{AF}$} \\
\hline No & 1019 & 95.8 \\
\hline Yes & 45 & 4.2 \\
\hline \multicolumn{3}{|l|}{ LVEF <50\% } \\
\hline No & 837 & 78.7 \\
\hline Yes & 227 & 21.3 \\
\hline \multicolumn{3}{|c|}{ Creatinine $\geq 200 \mu \mathrm{mol} / \mathrm{L}$} \\
\hline No & 1026 & 96.4 \\
\hline Yes & 38 & 3.6 \\
\hline \multicolumn{3}{|l|}{$\mathrm{DM}$} \\
\hline No & 618 & 58.1 \\
\hline Yes & 446 & 41.9 \\
\hline \multicolumn{3}{|c|}{ Preoperative IABP } \\
\hline No & 1024 & 96.2 \\
\hline Yes & 40 & 3.8 \\
\hline \multicolumn{3}{|c|}{ Urgent/emergency } \\
\hline No & 757 & 71.1 \\
\hline Yes & 307 & 28.9 \\
\hline \multicolumn{3}{|l|}{ Vessel disease } \\
\hline DIAG & 58 & 5.5 \\
\hline $\mathrm{CX}$ or RCA & 265 & 24.9 \\
\hline $\mathrm{CX}$ and RCA & 741 & 69.6 \\
\hline \multicolumn{3}{|l|}{ LMD } \\
\hline No & 807 & 75.8 \\
\hline Yes & 257 & 24.2 \\
\hline
\end{tabular}

TABLE E1. Continued

\begin{tabular}{lrc}
\hline Variable & $\mathbf{N}$ & $\%$ \\
\hline CPB & & \\
No & 694 & 65.2 \\
Yes & 370 & 34.8 \\
Overall & 1064 & \\
\hline
\end{tabular}

NYHA, New York Heart Association; $M I$, myocardial infarction; $P C I$, percutaneous coronary intervention; $C O P D$, chronic obstructive pulmonary disease; $C V A$, cerebrovascular accident; $P V D$, peripheral vascular disease; $A F$, atrial fibrillation; $L V E F$, left ventricular ejection fraction; $I A B P$, intra-aortic balloon pump; $C X$, circumflex artery; $R C A$, right coronary artery; $L M D$, left main stem disease; $C P B$, cardiopulmonary bypass; $D M$, diabetes mellitus; DIAG, diagonal.

TABLE E2. Short-term outcomes in the unmatched patients with a single internal thoracic artery $($ SITA) $(n=1064)$

\begin{tabular}{|c|c|c|}
\hline Outcomes & $\mathbf{N}$ & $\%$ \\
\hline \multicolumn{3}{|l|}{ 30-d mortality } \\
\hline No & 1047 & 98.4 \\
\hline Yes & 17 & 1.6 \\
\hline \multicolumn{3}{|l|}{ DSWI } \\
\hline No & 1025 & 96.3 \\
\hline Yes & 39 & 3.7 \\
\hline \multicolumn{3}{|c|}{ Postoperative CVA } \\
\hline No & 1052 & 98.9 \\
\hline Yes & 12 & 1.1 \\
\hline \multicolumn{3}{|c|}{ Postoperative RRT } \\
\hline No & 993 & 93.3 \\
\hline Yes & 71 & 6.7 \\
\hline \multicolumn{3}{|l|}{ POAF } \\
\hline No & 781 & 73.4 \\
\hline Yes & 283 & 26.6 \\
\hline \multicolumn{3}{|l|}{ Reintubation } \\
\hline No & 1009 & 94.8 \\
\hline Yes & 55 & 5.2 \\
\hline \multicolumn{3}{|l|}{ Reexploration } \\
\hline No & 1015 & 95.4 \\
\hline Yes & 49 & 4.6 \\
\hline \multicolumn{3}{|c|}{ Prolonged hospital stay length ( $\geq 8 \mathrm{~d}$ ) } \\
\hline No & 514 & 48.3 \\
\hline Yes & 550 & 51.7 \\
\hline
\end{tabular}

